\title{
La agricultura andina y su problemática
}

J Selva Andina Biosph. 2019;7(1):1-2.

Una actividad de sustento familiar, llena de profundas contradicciones y desigualdades agrarias. Las Naciones Unidas el año 2014 concibieron en un llamado a concentrar la atención mundial en la importancia del rol de la agricultura familiar, a pequeña escala, a fin de disminuir el hambre, la pobreza, seguridad alimentaria, mejorar la gestión de los recursos naturales, protección del medio ambiente y lograr el desarrollo sostenible, en particular en zonas rurales. La tradición social rural en Latinoamérica, en el siglo XX, estaba evidenciada por las luchas e identidad de movimientos campesinos, que viven trabajando sus tierras para el progreso de su vida familiar y colectiva, sea en asociaciones, cooperativas, comunas u otras formas de organización, para batallar por sus derechos y de todos los desposeídos del campo y la ciudad.

Otra problemática de la agricultura campesina y familiar son las estructuras, como el acceso, tenencia y propiedad sobre la tierra y el agua, la creación de fuentes de trabajo y el sostenimiento de las poblaciones en zonas rurales. Los campesinos laboran en sus propias parcelas, también son aparceros o arrendatarios siendo un sector social cada vez más explotado y pobre.

La acumulación de tierras y territorios hoy en día es el primer factor en la destrucción de la agricultura familiar y la economía campesina. En la actualidad, la realidad agrícola campesina está determinada por el tipo de territorio montañoso y de altura otorgando al problema de la tierra otras características.

El sistema de haciendas de nuestros países que se fue robusteciendo luego de la independencia a costa de la usurpación de las tierras comunales es un modo de dominación y explotación social de los indígenas. Una apreciación general de la población de los campesinos andinos, señala que un tercio vive en el campo conservando un nivel de autoabastecimiento alimentario. Las tres cuartas partes de lo que consumen son productos nacionales, cuyo peso en la producción campesina representa un $40 \%$ aproximadamente, del conjunto de los alimentos, sin embargo persiste el nivel de pobreza rural con alrededor del 60\%, con desnutrición asentada en zonas rurales del $26 \%$. Además, países andinos mantienen una alta inequidad en el acceso a recursos naturales en el campo, también se hace hincapié que superan $50 \%$ de unidades productivas del agro con un rango entre 0 y 5 hectáreas, lo contrario sucede con las unidades de producción mayores a 200 hectáreas representan menos del $1 \%$.

El campesinado andino no comercializa la totalidad de la producción como es el caso de la agricultura empresarial, en lo relacionado a los insumos, se limitan al máximo a comprar, se basan en el autoconsumo y el reciclaje de subproductos.

En casi todos los países andinos, los Gobiernos han reemplazado el concepto de campesinado por "agricultura familiar" en sus políticas de desarrollo rural. Los campesinados latinoamericanos afrontan el nuevo milenio excluidos del sistema. Producen en condiciones precarias, productos que carecen de compradores en el 


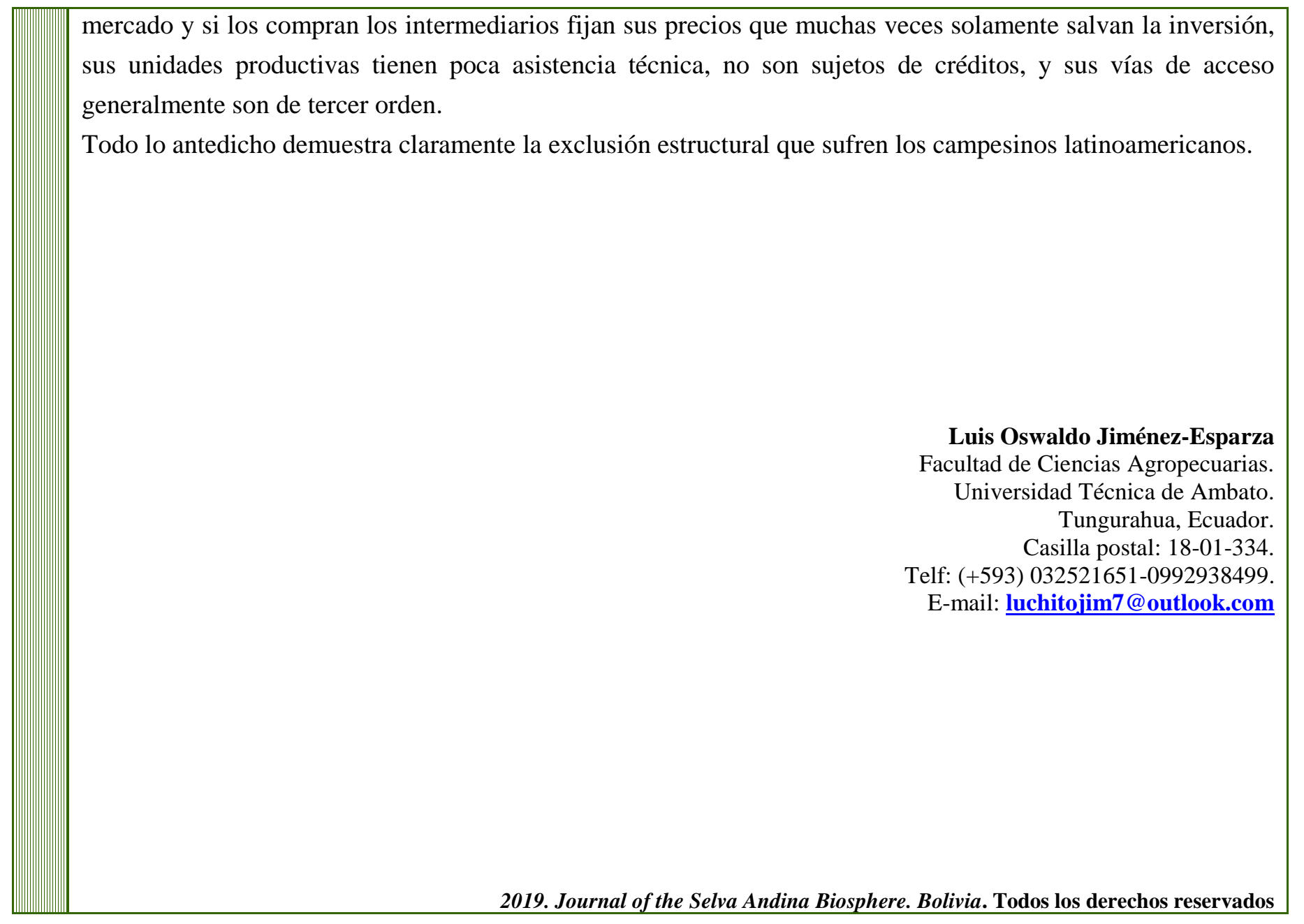

